\title{
Metastatic Diagnosis
}

National Cancer Institute

\section{Source}

National Cancer Institute. Metastatic Diagnosis. NCI Thesaurus. Code C162221.

Any diagnosis indicating the presence of metastatic disease. 